\title{
Study on the Large Deformation Characteristics and Disaster Mechanism of a Thin-Layer Soft-Rock Tunnel
}

\author{
Xiulian Zhang, ${ }^{1,2}$ Manchao He, ${ }^{1,2}$ Fengnian Wang, ${ }^{1,2}$ Gan $\mathrm{Li}^{3}$ Shengxin $\mathrm{Xu},{ }^{4}$ \\ and Zhigang Tao $\mathbb{D}^{1,2}$ \\ ${ }^{1}$ State Key Laboratory for Geomechanics and Deep Underground Engineering, China University of Mining and \\ Technology (Beijing), Beijing 100083, China \\ ${ }^{2}$ School of Mechanics and Civil Engineering, China University of Mining and Technology (Beijing), Beijing 100083, China \\ ${ }^{3}$ State Key Laboratory of Hydroscience and Engineering, Tsinghua University, Beijing 100084, China \\ ${ }^{4}$ Deformation Survey Center, Yunnan Earthquake Agency, Kunming 650041, China
}

Correspondence should be addressed to Zhigang Tao; taozhigang@263.net

Received 20 May 2020; Revised 18 July 2020; Accepted 23 July 2020; Published 13 August 2020

Academic Editor: Wen-Chieh Cheng

Copyright ( 2020 Xiulian Zhang et al. This is an open access article distributed under the Creative Commons Attribution License, which permits unrestricted use, distribution, and reproduction in any medium, provided the original work is properly cited.

\begin{abstract}
In view of the large deformation of thin-layer soft rock in the No. 2 inclined shaft of the Muzhailing Tunnel, we performed an experimental investigation on the mineral composition, physical characteristics, and uniaxial compressive strength of the surrounding rock of the tunnel. The characteristics of the large deformation of the surrounding rock of the tunnel were analyzed, and the main factors influencing the deformation of the tunnel were revealed. The influence of various factors on the large deformation of the surrounding rock was analyzed using the 3DEC-Trigon discrete element numerical simulation method. The results show that (1) the deformation of the surrounding rock of the tunnel has remarkable asymmetry, the deformation of the initial support of the tunnel is significant, and the buried depth of the area where the maximum deformation of the tunnel exceeded $1 \mathrm{~m}$ is greater than $500 \mathrm{~m}$; (2) the main factors influencing the deformation of a thin-layer slate tunnel include joint inclination, buried depth, water absorption, and softening of the surrounding rock; and (3) the maximum deformation of the surrounding rock is observed for a joint angle of $45^{\circ}$, at which the buried depth is directly proportional to the deformation and failure of the tunnel. Furthermore, after the surrounding rock was softened by water absorption, the floor of the tunnel, the left shoulder socket, and the right side of the tunnel are deformed greatly. The results of this study will provide a theoretical basis for the study of similar deformation control methods and supporting measures for tunnels excavated in thin-layer soft rock.
\end{abstract}

\section{Introduction}

The Muzhailing Tunnel in China is a critical control project along the Weiwu Expressway from Lanzhou to Haikou (G75), a national expressway. Because of its special geological conditions including deep burial, high ground stress, and a thin-layered slate structure, the tunnel deformation is extremely serious and has restricted the opening of the Weiwu Expressway. During the construction process, tunnel deformation and collapse occur frequently because of disturbance from excavation and the complex geological structure, seriously affecting the safety of the tunnel project [1-4]. Therefore, it is urgent to investigate the deformation mechanism of the surrounding rock of the thin-layered slate tunnel to provide an important theoretical basis for support and control measures after future deformation of the surrounding rock.

Many researchers have investigated the deformation of deep-buried tunnels and have obtained useful findings [5-8]. In 1999, Brox and Hagedorn [9] studied the deformation characteristics of a tunnel crossing a fault along the Anatolian Highway in Turkey. The study revealed that structural stresses, weak surrounding rock, and stress concentrations after excavation were the main causes of the deformation of the tunnel. In 2000, Hoek and Marinos [10] identified through a study of rock and rock mass strength that rock mass strength and ground stress were the key factors affecting the stability of the surrounding rock of the 
tunnel. In 2005, Liu et al. [11] studied the damage characteristics and causes of the large deformation of the Muzhailing Tunnel and suggested that the deformation and failure of the tunnel had serious, long-term and asymmetric characteristics. The deformation was found to be mainly caused by the plastic flow and expansion of the excavated unloaded surrounding rock under the combined action of lithology, groundwater, and ground stress field.

Apart from experimental investigations, many studies have numerically analyzed the deformation of deeply buried tunnels. In 2006, Meguid and Rowe [12] studied the deformation and stress distribution of the surrounding rock of a tunnel under different stress conditions by means of a three-dimensional numerical simulation method. Guo et al. [13] analyzed the anisotropy of the strength and deformation of layered surrounding rock through an experiment of basic mechanics and studied the deformation and failure mechanism of the highly stressed and steeply dipping layer of the Yangjiaping Tunnel by numerical analysis. Yu [14] in 2017 studied the deformation mechanism and control measures of the Shiziyuan Tunnel by means of theoretical analysis and on-site measurement and found that the main factors of the deformation were ground stresses, mechanical characteristics of surrounding rocks, type of tunnel-lining structure, and construction disturbance (blasting). In 2018, Cao et al. [15] analyzed the deformation and failure characteristics of the initial support of a typical weak tunnel, Dongshan Tunnel, and obtained the factors influencing the stability of surrounding rocks in the construction process. Sun et al. [16] in 2019 studied the application of a constant resistance large deformation anchor cable support system by performing a field test and numerical simulation. The results showed that the anchor cable effectively controlled the large deformation of the surrounding rock of the tunnel.

The above studies have revealed many beneficial findings on deep-buried soft-rock tunnels. However, there are few studies on the deformation and failure mechanisms of the surrounding rock in the complex engineering geological environment of the Muzhailing deep-buried thin-layered slate tunnel. The factors affecting large deformations of the surrounding rock and the degree of influence of each factor on the deformation of the surrounding rock of the tunnel are not adequately understood. Therefore, it is necessary to postulate relevant theories and perform numerical analysis.

This study considers the No. 2 inclined shaft of the Muzhailing Tunnel, investigating the deformation characteristics of the thin-layered slate tunnel by statistically analyzing the deformation of the tunnel under the original supporting conditions. Combined with laboratory experiments, the main factors affecting tunnel deformation are then analyzed. At the same time, the effects of different joint inclinations of the surrounding rock, buried depths, water absorption, and softening on the large deformation of the surrounding rock are analyzed by the 3DEC-Tragon numerical simulation method.

\section{Project Overview}

The Muzhailing Tunnel is located in the low and middle mountainous area of the West Qinling Mountains (Figure 1). It is located at the junction of several plates, crosses the Muzhailing Watershed between the Zhanghe River and Taohe River and spans Zhangxian County and Minxian County of Gansu Province. The total length of the tunnel is $15.15 \mathrm{~km}$, the maximum buried depth of the tunnel body is $629.1 \mathrm{~m}$, and the minimum buried depth is $8 \mathrm{~m}$. The tunnel is composed of three inclined shafts, of which the No. 2 inclined shaft is located in the Muzhailing Tunnel (middle section, red framed position in Figure 1). The starting and ending pile numbers are $(z) \mathrm{K} 216+380-(z) \mathrm{K} 220+300$, and the length of the Muzhailing Tunnel is $3920 \mathrm{~m}$. The opening of the No. 2 inclined shaft is located on the north side slope of Luzagou. The pile number in the main tunnel at its intersection with the inclined shaft is $\mathrm{K} 218+400$. The intersection angle with the main tunnel plane is $90^{\circ}$. For the inclined shaft, the starting pile number is $\mathrm{K} 0+000$ and the end pile number is $K 1+813 \mathrm{~m}$, with the length of the shaft being $1813 \mathrm{~m}$.

2.1. Formation Lithology Characteristics. According to the field investigation and exploration, the bank slope is covered with quaternary slope gravel and the underlying bedrock is the lower Permian slate. The main components of the surrounding rock are carbonaceous slate with local intercalations of sandstone, limestone, and shale. Quartzite is sporadically distributed in the rock formations, and the slate in this area is mainly grey-black. Joints are relatively developed, the rock mass is relatively broken, and the strength markedly decreases under the action of water-rock coupling. The surrounding geological structure largely affects the surrounding rock, and the whole area is essentially grade $\mathrm{V}$ rock.

2.2. Hydrogeological Characteristics. The distribution of groundwater was relatively uneven and was strongly related to the geological structure, lithology, and topography of the region. As the area was strongly affected by geological actions in the past, the joints and fissures in the area were well developed and the groundwater mainly was present in the form of fissure water. According to the geological survey, the valley area was relatively rich in water content and the water collection capacity was strong, so the water pouring was more serious when the tunnel passes through the area. Besides fissure water, karst water and Quaternary loose rock void water were encountered in this area.

2.3. Ground Stress Characteristics. According to previous studies [17-19], hydraulic fracturing was used to measure the ground stress at two measurement points: $\mathrm{AK} 214+738 \mathrm{~m}$ and $\mathrm{AK} 219+422.8 \mathrm{~m}$, at test depths of 492.00 and $499.00 \mathrm{~m}$, respectively. According to the test results, the stress condition was such that the horizontal maximum principal stress $S_{H}$ was greater than the horizontal minimum principal stress $S_{h}$, which was greater than the straight principal stress $S_{v}$. The ground stress was mainly tectonic stress. The ratio of stress size to $R_{c}$ in the Muzhailing Tunnel area is shown in Table 1. 


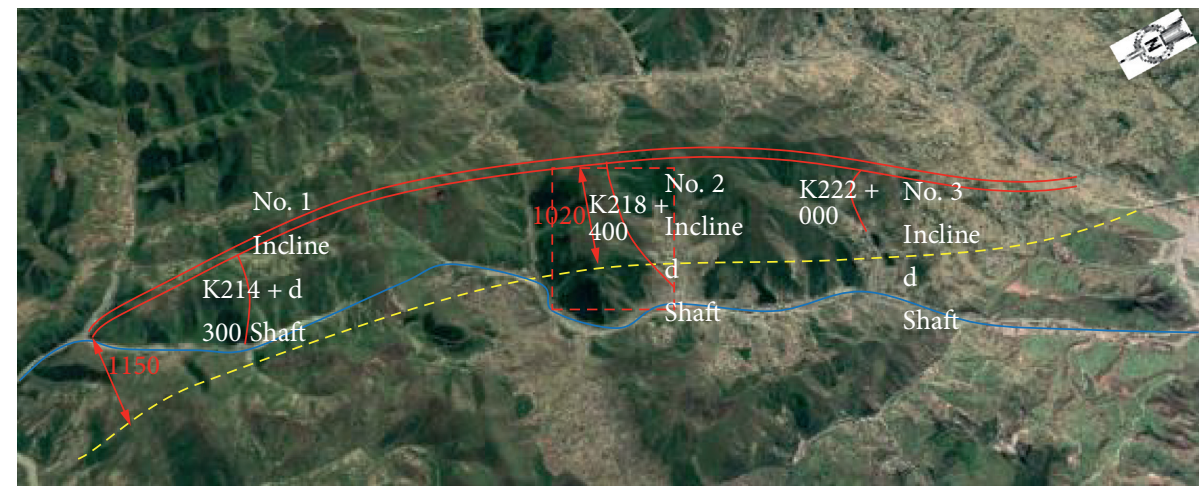

Lanzhou-Chongqing Railway-Muzhailing Tunnel

- G75expressway-Muzhailing Tunnel

— G212National Highway

Figure 1: Location of the Muzhailing Tunnel and the no. 2 inclined shaft.

TABLE 1: Ratio of crustal stress to $R_{c}$ in the Muzhailing Tunnel area.

\begin{tabular}{lcccc}
\hline No. & Measuring depth & $S_{H}(\mathrm{MPa})$ & $R_{C}(\mathrm{MPa})$ & $R_{C} / S_{H}$ \\
\hline 1 & 250 & 11.37 & $20-30$ & $1.76-2.64$ \\
2 & 270 & 12.14 & $20-30$ & $1.65-2.47$ \\
3 & 300 & 11.37 & $20-30$ & $1.76-2.64$ \\
4 & 320 & 14.93 & $20-30$ & $1.34-2.01$ \\
5 & 365 & 14.84 & $20-30$ & $1.35-2.02$ \\
6 & 370 & 17.98 & $20-30$ & $1.11-1.67$ \\
7 & 397 & 16.28 & $20-30$ & $1.23-1.84$ \\
8 & 427 & 18.76 & $20-30$ & $1.07-1.60$ \\
\hline
\end{tabular}

According to the Standard for Engineering Classification of Rock Mass (GB/50218-94), $R_{c} / S_{H}<4$ is extremely high stress, $4<R_{c} / S_{H}<7$ is high stress, and $7<R_{c} / S_{H}$ is low stress. Table 1 shows that the value of $R_{C} / S_{H}$ in the Muzhailing Tunnel is $<4$, which is categorized as extremely high ground stress. Moreover, the stratum rock mass is relatively broken and the possibility of large deformation in the surrounding rock of the tunnel is relatively high.

2.4. Properties of Rock Mass. The surrounding rock inclination angles and surrounding rock integrity of the No. 2 inclined shaft of the Muzhailing Tunnel in the large deformation area vary widely. The dominant joint angle is between $30^{\circ}$ and $85^{\circ}$, and the thickness of the slate layer is $5-30 \mathrm{~cm}$. To understand the mineral composition and mechanical properties of the slate, an X-ray diffraction experiment, a point-load experiment, and a uniaxial compression experiment were performed.

2.4.1. Mineral Composition Analysis. Six positions (pile number K1430/K1460/K1490/K1520/K1550/K1570) in the No. 2 inclined shafts of the Muzhailing Tunnel were selected as sampling points, and the selected carbonaceous slate samples were quantitatively analyzed by using a TTR III multifunctional X-ray diffractometer. The mineral composition and relative content of rock and clay were obtained as shown in Tables 2 and 3. A small difference was observed in the mineral composition among the six groups, particularly in the quartz and clay minerals, which mainly included illite, chlorite, illite mixed layer, and kaolinite. The montmorillonite content was low, and the samples exhibited low water absorption and expansion.

2.4.2. Effect of Water on the Strength of Slate. Because of the fissured joints and severe weathering of the surrounding rock of the No. 2 inclined shaft of the Muzhailing Tunnel, the lithology is mainly carbonaceous slate with scattered sandstones. The rock samples were significantly affected by the disturbance during sample acquisition, and the processing of standard samples was found to be challenging. Therefore, a field point load intensity meter was selected for a rapid experimental analysis. During the selection of specimens, the integrity of the selected rock should be ensured (avoiding rocks with cracks). A total of 82 specimens of carbonaceous slate from K1740 to K1800 in the No. 2 inclined shaft were selected in the field, of which 41 specimens were tested for uniaxial compressive strength in the natural state, and the other 41 specimens were tested for uniaxial compressive strength after 24 hours of water absorption. The experimental results for the 82 specimens are shown in Figure 2.

The uniaxial compressive strength was estimated by the point-load method, and the average uniaxial compressive strength of the carbonaceous slate in the natural state was found to be $29.6 \mathrm{MPa}$. The average uniaxial compressive strength of the carbonaceous slate after water absorption for 24 hours was $12.7 \mathrm{MPa}$. The uniaxial compressive strength after water absorption was reduced by $57 \%$ when compared with the natural state.

2.4.3. Uniaxial Compressive Strength Test. Slate with visible joints was processed into standard $\Phi 50 \mathrm{~mm} \times 100 \mathrm{~mm}$ specimens. Specimens with $30^{\circ}, 45^{\circ}$, and $60^{\circ}$ bedding inclinations were tested for their uniaxial compressive strength by using a $2000 \mathrm{kN}$ capacity mono-triaxial test system. This test revealed the influence of different joint surface 
TABLE 2: Relative content of different minerals in the rock mass.

\begin{tabular}{|c|c|c|c|c|c|c|c|}
\hline \multirow{2}{*}{ No. } & \multicolumn{7}{|c|}{ Mineral content (\%) } \\
\hline & Quartz & Potash feldspar & Plagioclase & Siderite & Pyrite & Dolomite & Clay mineral \\
\hline 1 & 43.8 & 1.0 & 2.2 & - & - & - & 53.0 \\
\hline 2 & 48.1 & - & - & - & - & - & 51.9 \\
\hline 3 & 56.5 & - & 1.5 & - & - & - & 42.0 \\
\hline 4 & 50.9 & 0.9 & 1.8 & - & - & - & 46.4 \\
\hline 5 & 50.3 & 1.0 & 1.8 & - & - & - & 46.9 \\
\hline 6 & 48.0 & 0.9 & 1.6 & - & 2.1 & - & 47.4 \\
\hline
\end{tabular}

TABLE 3: Relative content of different minerals in the clay mass.

\begin{tabular}{|c|c|c|c|c|c|c|c|c|c|}
\hline \multirow{2}{*}{ No. } & \multicolumn{7}{|c|}{ Relative content of clay minerals (\%) } & \multicolumn{2}{|c|}{$\begin{array}{c}\text { Mixed layer ratio } \\
(\% S)\end{array}$} \\
\hline & $S$ & $I / S$ & $I$ & $K$ & $C$ & $C / S$ & Py & $I / S$ & $C / S$ \\
\hline 1 & - & 16 & 44 & 10 & 25 & - & 5 & 10 & - \\
\hline 2 & 3 & 16 & 47 & 9 & 25 & - & - & 5 & - \\
\hline 3 & 2 & 12 & 46 & 8 & 32 & - & - & 5 & - \\
\hline 4 & - & 22 & 42 & 13 & 18 & - & 5 & 10 & - \\
\hline 5 & 一 & 20 & 37 & 11 & 27 & - & 5 & 10 & - \\
\hline 6 & 1 & 15 & 50 & 9 & 25 & - & - & 5 & - \\
\hline
\end{tabular}

Note. Ta: talc; Py: pyrophyllite; Se: serpentine; $V$ : vermiculite; $I / V$ : illite/vermiculite mixed layer; $S:$ smectite; $I / S$ : illite mixed layer; $I:$ illite; $K:$ kaolinite; $C$ : chlorite; $C / S$ : chlorite mixed layer.

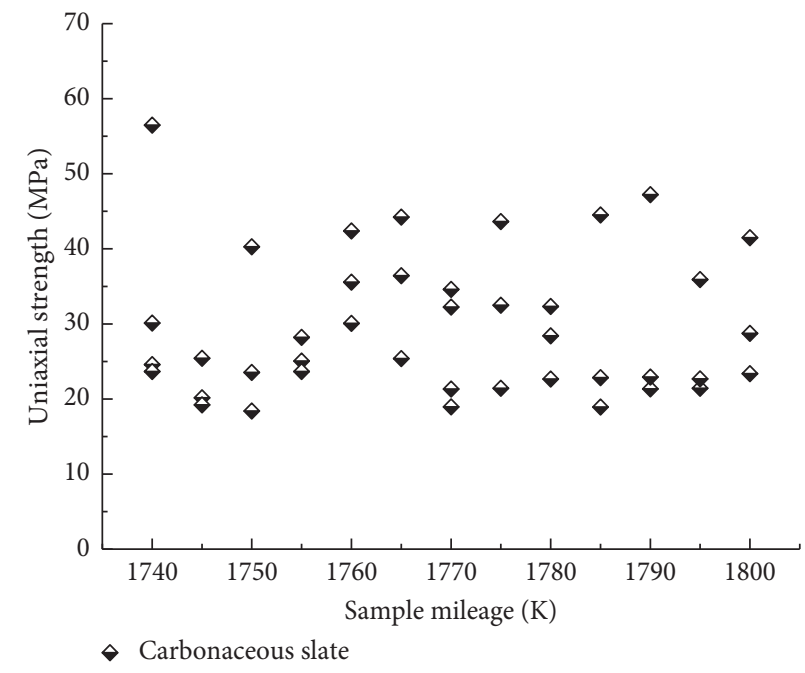

(a)

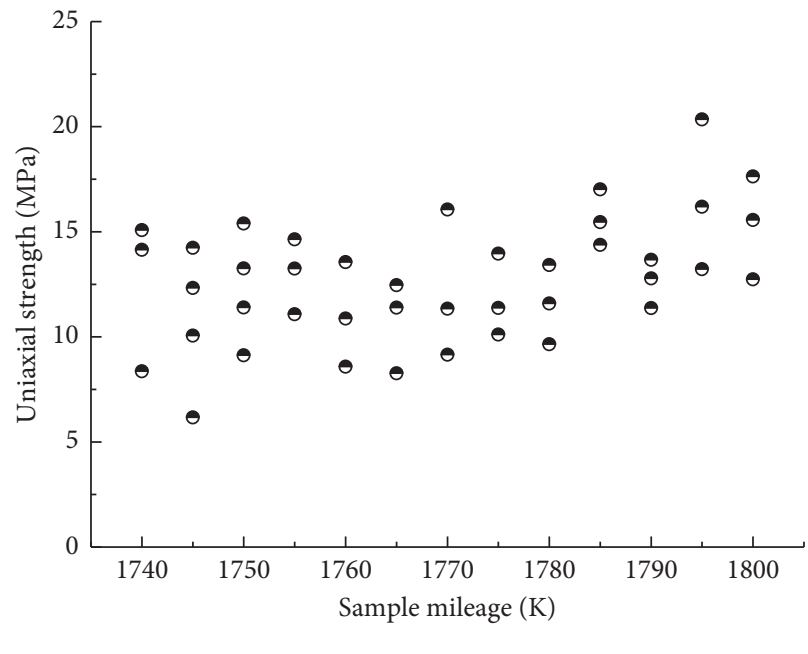

- Carbonaceous slate after water absorption

(b)

Figure 2: Uniaxial compressive strength of carbonaceous slate in the Muzhailing No. 2 inclined shaft: (a) compressive strength of carbonaceous slate in the natural state and (b) compressive strength of carbonaceous slate after water absorption.

inclinations on the strength of slate rock samples, as shown in Table 4.

According to the above results, the uniaxial compressive strength and elastic modulus of the rock specimens were relatively low when the joint surface of the three groups with different joint inclination angles was $45^{\circ}$ (that is, the angle between the joint surface and the horizontal plane was $45^{\circ}$ ). For inclination angles between $30^{\circ}$ and $60^{\circ}$, the surrounding rock essentially failed in shear.

\section{Analysis of Deformation Characteristics of the Surrounding Rock of the Tunnel}

3.1. Failure Characteristics of the Tunnel. To further study the large deformation characteristics of the surrounding rock of the Muzhailing Tunnel, we used a three-dimensional laser scanner and a total station together (Figure 3) to monitor eight sections of the No. 2 inclined shaft of the Muzhailing Tunnel, including XK0 + 060-XK0 + 250, XK0 + 
TABLE 4: Uniaxial compressive strength test results.

\begin{tabular}{|c|c|c|c|c|c|c|c|}
\hline No. & $\begin{array}{c}\text { Compressive } \\
\text { strength } \sigma_{c}(\mathrm{MPa})\end{array}$ & $\begin{array}{l}\text { Average value } \\
(\mathrm{MPa})\end{array}$ & $\begin{array}{c}\text { Elastic modulus } E \\
(\mathrm{GPa})\end{array}$ & $\begin{array}{c}\text { Average value } \\
(\mathrm{GPa})\end{array}$ & $\begin{array}{c}\text { Poisson's } \\
\text { atio } \mu\end{array}$ & $\begin{array}{c}\text { Average } \\
\text { value }\end{array}$ & Type of failure \\
\hline U30-1 & 89.1 & & 11.7 & & 0.1 & & Shear failure \\
\hline U30-2 & 82.8 & 74.3 & 12.5 & 11.9 & 0.1 & 0.1 & Shear failure \\
\hline U30-3 & 51.0 & & 11.5 & & 0.02 & & Shear failure \\
\hline U45-1 & 69.7 & & 12.6 & & 0.1 & & Shear failure \\
\hline U45-2 & 30.2 & 40.5 & 10.8 & 10.3 & 0.54 & 0.1 & Shear failure \\
\hline U45-3 & 21.5 & & 7.4 & & 0.003 & & Shear failure \\
\hline U60-1 & 63.0 & & 11.9 & & 0.1 & & Shear failure \\
\hline U60-2 & 65.8 & 63.0 & 13.0 & 12.3 & 0.03 & 0.08 & Shear failure \\
\hline U60-3 & 60.3 & & 12.1 & & 0.1 & & Shear failure \\
\hline
\end{tabular}

Note. For U30-1, 30 denotes joint inclination and 1 denotes rock number.

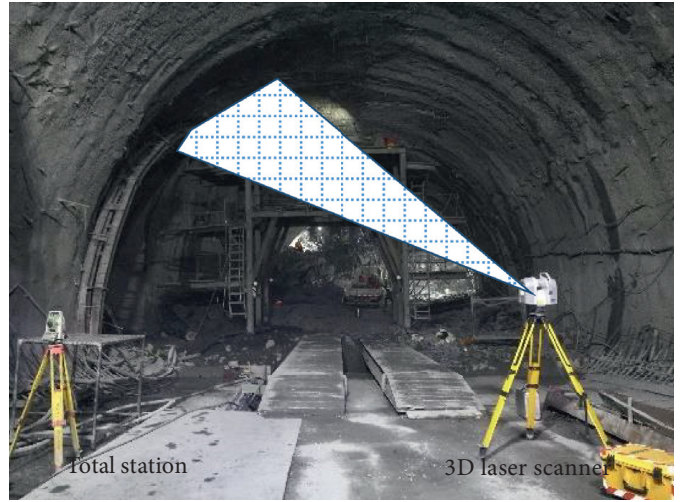

(a)

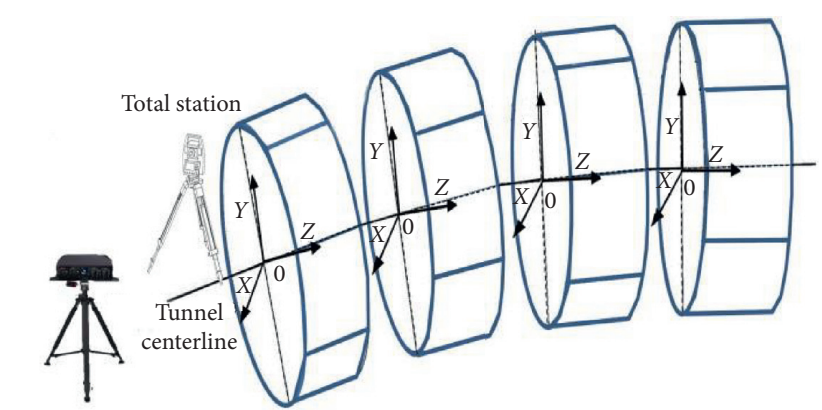

3D laser scanner

(b)

FIGURE 3: (a) Instrument for measuring the displacement of the surrounding rock of the tunnel and (b) monitoring schematic diagram of the displacement of the surrounding rock.

$250-\mathrm{XK} 0+410, \quad \mathrm{XK} 0+764-\mathrm{XK} 0+865, \quad \mathrm{XK} 1+010-\mathrm{XK} 1+$ $115, \quad \mathrm{XK} 1+330-\mathrm{XK} 1+380, \quad \mathrm{XK} 1+525-\mathrm{XK} 1+564$ $\mathrm{XK} 1+564-\mathrm{XK} 1+587$, and XK1 +622-XK1 +666. The results of the monitoring are shown in Table 2. Figure 4 shows the initial support damage as photographed on-site. According to Table 5 and Figure 4, the initial deformation and cracking of the tunnel support were severe, the steel frame was distorted, the deformation rate was high, and the amount of deformation was large.

3.2. Deformation Characteristics of Surrounding Rock. On the basis of the deformation of the surrounding rock of the No. 2 inclined shaft, the deformation of the surrounding rock of the tunnel was classified according to the standard of tunnel deformation. The length of the tunnel was $\mathrm{K} 1713 \mathrm{~m}$, which is divided into four zones: basic stable zone (maximum deformation of less than $100 \mathrm{~mm}$ ), slight deformation zone (maximum deformation of 100-250 mm), larger deformation zone (maximum deformation of 250-1000 $\mathrm{mm}$ ), and severe deformation zone (deformation of more than $1000 \mathrm{~mm}$ ). Through the above analysis, $41 \%$ of the total length of the tunnel was found to be in the large deformation zone and the buried depth of the severe deformation zone was more than $500 \mathrm{~m}$. The length of the basic stable, slight deformation, larger deformation, and severe deformation zones were 407, 250, 717, and $338 \mathrm{~m}$, respectively.

The deformation of the surrounding rock in the essentially stable area was analyzed in this study. After the initial support of the tunnel was completed, the deformation of the surrounding rock increased sharply and the arch sank by $200-600 \mathrm{~mm}$. Generally, the tunnel reached basic stability within 14 to 18 days, while the deformation continued by 1-2 $\mathrm{mm}$ per day. From the displacement distribution along the entire section, the deformation of the tunnel in a given section was asymmetric: the deformation on the left side of the tunnel was significantly larger than that on the right side. Figure 5 shows the typical deformation curve of the surrounding rock.

From the field investigation, the laboratory experiments, and the analysis of the field-monitoring data, we found that the surrounding rock joints of the No. 2 inclined shaft of the Muzhailing Tunnel were developed, the slate layer spacing was $5-30 \mathrm{~cm}$, and the structure largely influenced the strength of the rock mass. The mineral content of the slate clay was approximately $50 \%$, indicating that the rock strength had a certain influence on the damage of the surrounding rock and that water largely influenced the rock strength. The stress distribution of the surrounding rock varied with an increase in buried depth. The area around the 


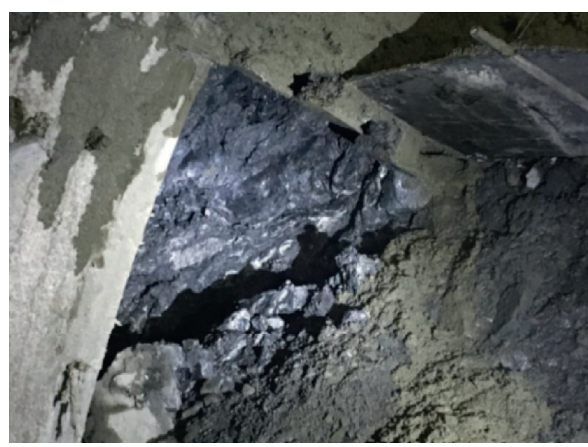

(a)

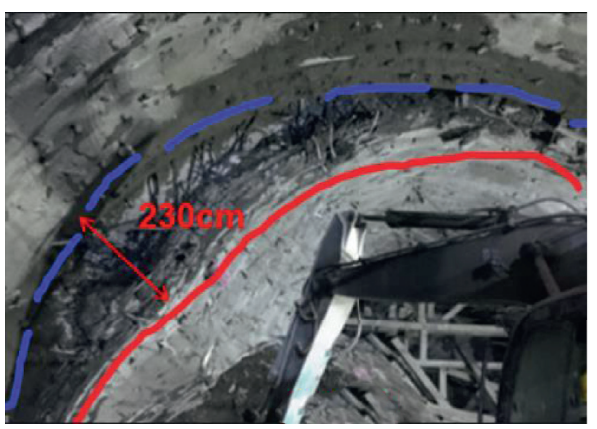

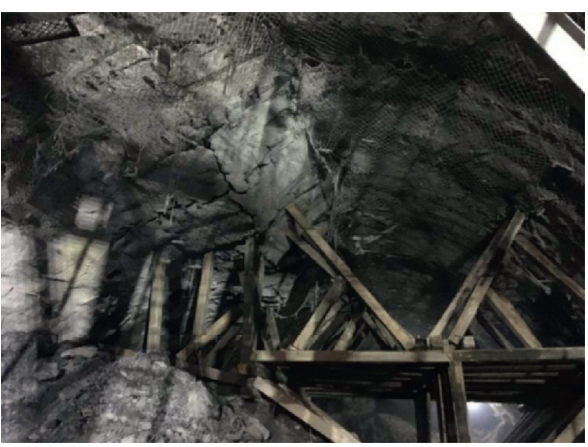

(b)

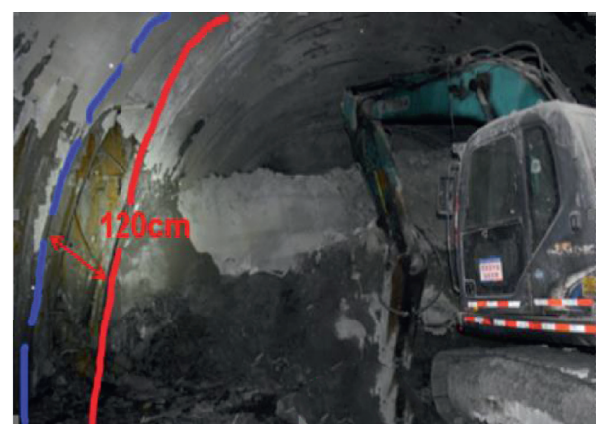

(c)

FIgURe 4: Damage characteristics of the surrounding rock of the tunnel: (a) severe drip of water in the middle steps on the left, (b) severe deformation of the arch, and (c) large deformation of the local vault.

TABLE 5: Results of the monitoring of the initial support of the tunnel.

\begin{tabular}{|c|c|c|c|c|c|}
\hline Monitoring section & $\begin{array}{l}\text { Buried } \\
\text { depth } \\
(\mathrm{m})\end{array}$ & Surrounding rock lithology & $\begin{array}{c}\text { Cumulative } \\
\text { sinking } \\
(\mathrm{mm})\end{array}$ & $\begin{array}{l}\text { Cumulative } \\
\text { convergence } \\
\text { value }(\mathrm{mm})\end{array}$ & $\begin{array}{l}\text { Maximum deformation } \\
\text { convergence rate }(\mathrm{mm} / \mathrm{d})\end{array}$ \\
\hline $\mathrm{XK} 0+060-\mathrm{XK} 0+250$ & $35-137$ & $\begin{array}{l}\text { Fault fracture zone, strong compression, } \\
\text { and torsion of the surrounding rock }\end{array}$ & $120-180$ & $150-430$ & - \\
\hline $\mathrm{XK} 0+060-\mathrm{XK} 0+250$ & $137-215$ & $\begin{array}{l}\text { Fault fracture zone, strong compression, } \\
\text { and torsion of the surrounding rock }\end{array}$ & $230-327$ & $300-580$ & - \\
\hline $\mathrm{XK} 0+764-\mathrm{XK} 0+865$ & $280-290$ & $\begin{array}{l}\text { Interlayer of the sandy slate and } \\
\text { carbonaceous slate }\end{array}$ & $250-427$ & $320-600$ & - \\
\hline $\mathrm{XK} 1+010-\mathrm{XK} 1+115$ & $309-352$ & Carbonaceous slate & $500-750$ & $650-1550$ & 560 \\
\hline $\mathrm{XK} 1+330-\mathrm{XK} 1+380$ & $447-474$ & Thin-layer carbonaceous slate & $240-513$ & $637-1224$ & 174 \\
\hline $\mathrm{XK} 1+525-\mathrm{XK} 1+564$ & $568-597$ & Thin-layer carbonaceous slate & $240-565$ & $637-3145$ & 831 \\
\hline $\mathrm{XK} 1+564-\mathrm{XK} 1+587$ & $590-597$ & Thin-layer slate & $291-467$ & $657-1205$ & 57 \\
\hline $\mathrm{XK} 1+622-\mathrm{XK} 1+666$ & $548-569$ & $\begin{array}{c}\text { Thin-layer slate with stranded water } \\
\text { flowing out }\end{array}$ & $140-458$ & $127-2936$ & 814 \\
\hline
\end{tabular}

Muzhailing Tunnel experienced extremely high ground stress, and the deformation of the surrounding rock was significant.

Therefore, three main factors influencing tunnel deformation were determined from the experimental study: joint inclination angle variation of the surrounding rock, attenuation of the strength of the surrounding rock owing to water absorption, and the buried depth of the tunnel. To further reveal the deformation and failure mechanism of the surrounding rock of the Muzhailing Tunnel, a numerical simulation was performed by considering these three aspects: joint inclination angle, burial depth, and softening caused by water absorption.

\section{Numerical Analysis of the Deformation Mechanism of the Thin-Layer Slate Tunnel}

4.1. Modelling Approach. The software 3 Dimension Distinct Element Code (3DEC) is a three-dimensional discrete element program that represents the discontinuous discrete characteristics of a material. It can explain the interaction between rock blocks and structural surfaces in rock masses, 


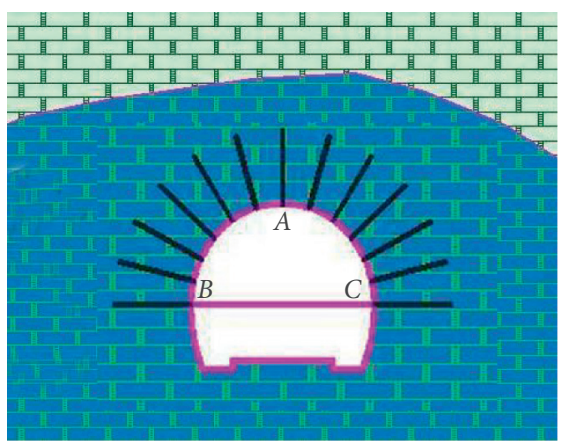

(a)

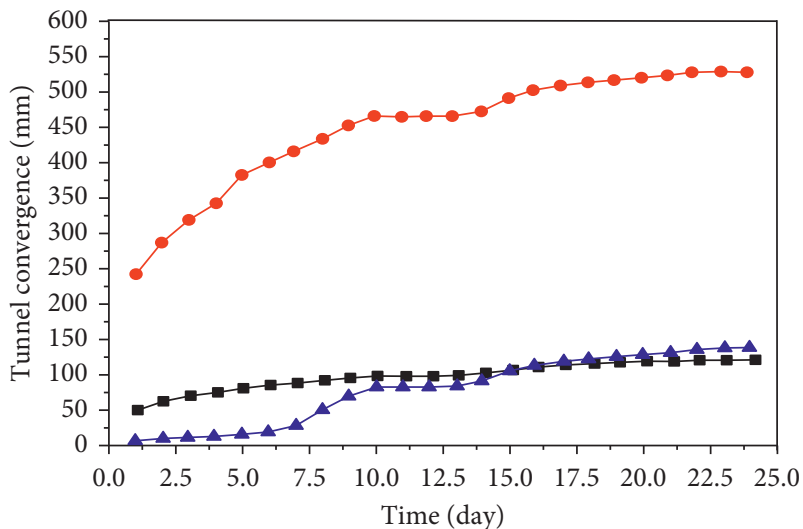

Convergence curve of measurement point $A$ at $615 \mathrm{~m}$ section

Convergence curve of measurement point $B$ at $615 \mathrm{~m}$ section

Convergence curve of measurement

point $C$ at $615 \mathrm{~m}$ section

(b)

Figure 5: (a) Distribution of tunnel-displacement monitoring points and (b) tunnel-displacement monitoring curve.

and it effectively simulates the realistic failure phenomenon of a rock mass. Cui et al. [20] used the discrete element 3DEC software to study the influence of the inclination of layered surrounding rock on the deformation of a tunnel. Their results demonstrated that the deformation of the surrounding rock of the tunnel primarily manifested in the form of block sliding and bending of the layered rock layer. Bahrani and Hadjigeorgiou [21] used the 3DEC joint constitutive model to study the deformation characteristics of layered rock mass in a roadway under the action of the supporting body. Hou [22] used the 3DEC numerical analysis software to analyze the deformation and failure characteristics of a roadway tunnel supported by an anchor mesh and obtained the stress distribution characteristics, displacement characteristics, and plastic zone distribution characteristics of the surrounding rock.

To determine the characteristics of prominent dominant joints and coexistence of multiple joint forms in the No. 2 inclined shaft of the Muzhailing Tunnel, a simulation method using equivalent ubiquitous joints of dominant joint groups was proposed in this study, as shown in Figure 6. Considering the computational cost, we did not individually simulate all joints in the numerical model and we generalized the distribution of surrounding rock joints as shown in Figure 6(b). The joints were grouped into dominant joint groups (Figure 6(c)) and other joints. Locally, other joints (except for superior joints) had anisotropic characteristics, while macroscopically they were regarded as isotropic. Therefore, the 3DEC-Trigon method was used to simulate the rock mass as continuous media equivalence. The simulation considered the representative elementary volume (REV) characteristics of the rock mass and the transformation of rock-to-rock mass parameters in the process of equivalence $[23,24]$. Compared with other methods, this method can better adapt to the actual characteristics of the surrounding rock of the Muzhailing Tunnel.

4.2. Determination of Numerical Simulation Parameters. According to the principle of joint parameter selection [25], joints were modelled as uniformly distributed. The mechanical properties of the rock were obtained from equations (1) to (4), and the edge length of the irregular blocks was selected as $\Delta z_{\min }=0.8$.

$$
\begin{aligned}
K & =\frac{E}{3(1-2 \mu)}, \\
G & =\frac{E}{2(1+\mu)}, \\
K_{n} & =10\left[\frac{K+(3 / 4) G}{\Delta z_{\min }}\right], \\
K_{s} & =0.4 K_{n},
\end{aligned}
$$

where $K$ is the bulk modulus, $G$ is the shear modulus, $K_{n}$ is the normal stiffness of the contact model parameters, and $K_{s}$ is the shear stiffness.

According to the geological strength index (GSI) rock classification standard [26-30], for the mechanical properties as obtained from equations (1) to (4), the numerical inversion analysis was used during the simulation process. Accordingly, the strengths of carbonaceous slate in the natural state and under the saturated condition were obtained as shown in Tables 6 and 7. On the basis of multiple numerical analyses, the REV with a stable structural plane combination was found to be $8 \times 8 \times 16 \mathrm{~m}$. The results of the numerical test on the uniaxial compressive strength of the rock mass are shown in Figure 7. 


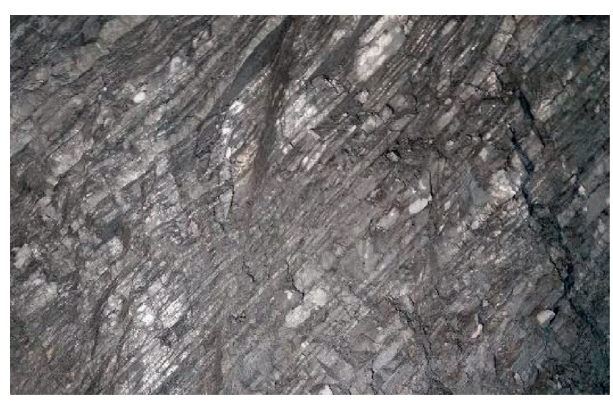

(a)

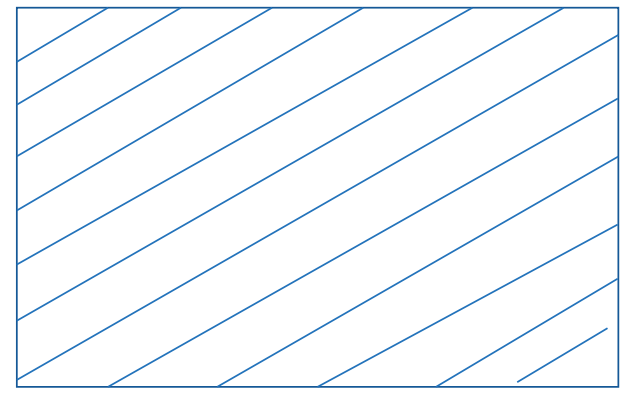

(c)

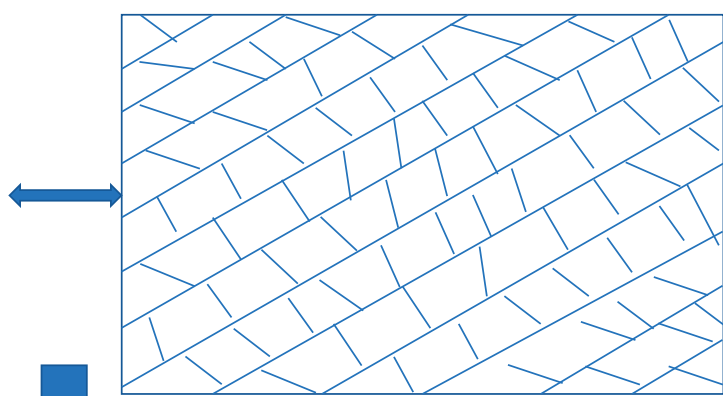

(b)

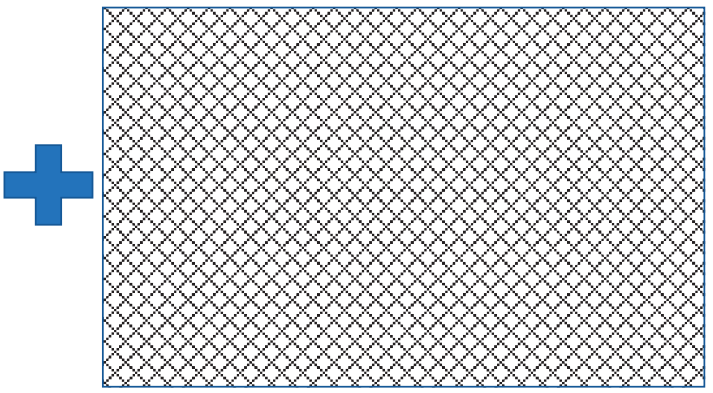

(d)

Figure 6: Modelling method of equivalent joints with dominant joints: (a) photo of the tunnel face, (b) generalization of the joint distribution, (c) dominant joints, and (d) equivalent joints.

After several inversion analyses combined with field measured deformation data of the surrounding rock, the dominant joint parameters selected were $j \mathrm{kn}=2 \mathrm{e} 9, \mathrm{jks}=1 \mathrm{e} 9$, $\mathrm{jcoh}=1 \mathrm{e} 5, \mathrm{jfr}=25$, and $\mathrm{jten}=5 \mathrm{e} 4$.

4.3. Establishment of the Numerical Model. A tunnel excavation model was established as shown in Figure 8. The model includes the tunnel section, uniform joints, and dominant joints. The ground stress was obtained from the field investigation as discussed in Section 2.3. The size of the model was $60 \mathrm{~m} \times 30 \mathrm{~m} \times 60 \mathrm{~m}$ (length $\times$ width $\times$ height). The reverse arch at the bottom of the tunnel was filled with concrete. Fixed constraints were imposed at the bottom of the model, and other boundary conditions were subjected to stress constraints based on the ground stress.

4.4. Effect of Joint Inclination on the Deformation of the Tunnel. Using the numerical model presented in Section 4.3, we estimated the ground stress when the buried depth was $500 \mathrm{~m}$. The vertical stress was $12.5 \mathrm{MPa}$, the maximum horizontal stress was $21 \mathrm{MPa}$, and the minimum horizontal stress was $12.5 \mathrm{MPa}$. This simulation did not consider the tunnel support. By changing the dominant joint angle, we analyzed the deformation characteristics, stress distribution, and plastic zone expansion of the surrounding rock under different joint inclination angles.
4.4.1. Variation in the Surrounding Rock Displacement under Different Joint Inclinations. As shown in Figure 9, bending deformation and block slip deformation were caused by tunnel excavation, with bending deformation being the primary deformation encountered by the tunnel. The maximum bending deformation occurred at the left shoulder socket of the tunnel. The bending deformation was mainly due to an increase in the deflection of the plate-like surrounding rock under the action of the ground stresses, and the slip deformation was mainly the result of the shear slip of the structural surface. The deformation of the tunnel was influenced by the presence of joints and was consequently asymmetric. Among the joint inclination angles of $30^{\circ}, 45^{\circ}$, and $60^{\circ}$, the most evident asymmetry was observed for a joint inclination angle of $45^{\circ}$. As shown in Figure 9, the displacement distribution is in the form of asymmetric butterfly displacement.

The maximum value of bending deformation corresponding to the $30^{\circ}$ joint inclination was $0.7 \mathrm{~m}$, and the displacement and deformation essentially stopped when the calculation reached 8000 steps. A separation layer developed at a depth of approximately $3.5 \mathrm{~m}$ in the surrounding rock, and sliding failure occurred in the surrounding rock of the tunnel. The maximum value of bending deformation corresponding to the $45^{\circ}$ joint inclination was $1.2 \mathrm{~m}$, and the displacement deformation essentially stopped after 10000 steps. A separation layer developed at a depth of approximately $7 \mathrm{~m}$ in the surrounding rock, the mass spalling caused by tunnel slip failure gradually increased, and the deformation of the surrounding rock of the tunnel presented strong 
TABLE 6: Strength of the carbonaceous slate rock mass.

\begin{tabular}{lccccccccc}
\hline \multirow{2}{*}{ Lithology } & \multicolumn{2}{c}{ Rock } & \multicolumn{3}{c}{ Constant } & \multicolumn{3}{c}{ Rock mass } \\
& $\sigma_{c i}(\mathrm{MPa})$ & $E_{i}(\mathrm{GPa})$ & & $m_{i}$ & $m_{b}$ & $s$ & $a$ & $\sigma_{c \mathrm{mass}}(\mathrm{MPa})$ & $E_{r m}(\mathrm{GPa})$ \\
\hline Carbonaceous slate in the natural state & 29.5 & 7.6 & 40 & 19 & 1.091 & 0.000335 & 0.511 & 7.4 & 0.6 \\
Carbonaceous slate in the saturated state & 11.7 & 2.8 & 37 & 5 & 0.249 & 0.000225 & 0.514 & 3.0 & 0.1 \\
\hline
\end{tabular}

Note. $E_{r m}$ : rock mass modulus; $\sigma_{c \text { mass }}$ : uniaxial compressive strength of the rock mass; $E_{i}$ : deformation modulus of the intact rock; $\sigma_{c i}$ : uniaxial compressive strength of the intact rock.

TABLE 7: Mechanical properties of the carbonaceous slate.

\begin{tabular}{|c|c|c|c|c|c|c|c|c|c|c|c|}
\hline \multirow[b]{2}{*}{ Lithology } & \multicolumn{6}{|c|}{ Rock mass parameters } & \multicolumn{5}{|c|}{ Structural plane parameters } \\
\hline & Density $\left(\mathrm{kg} / \mathrm{m}^{3}\right)$ & $\begin{array}{c}K \\
(\mathrm{GPa})\end{array}$ & $\begin{array}{c}G \\
(\mathrm{GPa})\end{array}$ & $\begin{array}{c}C^{b} \\
(\mathrm{MPa})\end{array}$ & $\varphi^{b}$ & $\begin{array}{c}\sigma_{t}^{b} \\
(\mathrm{MPa})\end{array}$ & $\begin{array}{c}K^{n} \\
(\mathrm{GPa})\end{array}$ & $\begin{array}{c}k^{s} \\
(\mathrm{GPa})\end{array}$ & $\begin{array}{c}C^{j} \\
(\mathrm{MPa})\end{array}$ & $\varphi^{j}$ & $\begin{array}{c}\sigma_{t}^{j} \\
(\mathrm{MPa})\end{array}$ \\
\hline $\begin{array}{l}\text { Carbonaceous slate in the } \\
\text { natural state }\end{array}$ & 2500 & 0.44 & 0.25 & 1.7 & 22 & 0.6 & 30.21 & 12.08 & 3.75 & 29 & 3.45 \\
\hline $\begin{array}{l}\text { Carbonaceous slate in the } \\
\text { saturated state }\end{array}$ & 2500 & 0.24 & 0.092 & 0.94 & 20 & 0.3 & 11.17 & 4.45 & 2.91 & 20 & 1.66 \\
\hline
\end{tabular}

Note. $\varphi$ : internal friction angle; $\sigma_{t}$ : tensile strength; $C$ : cohesion.

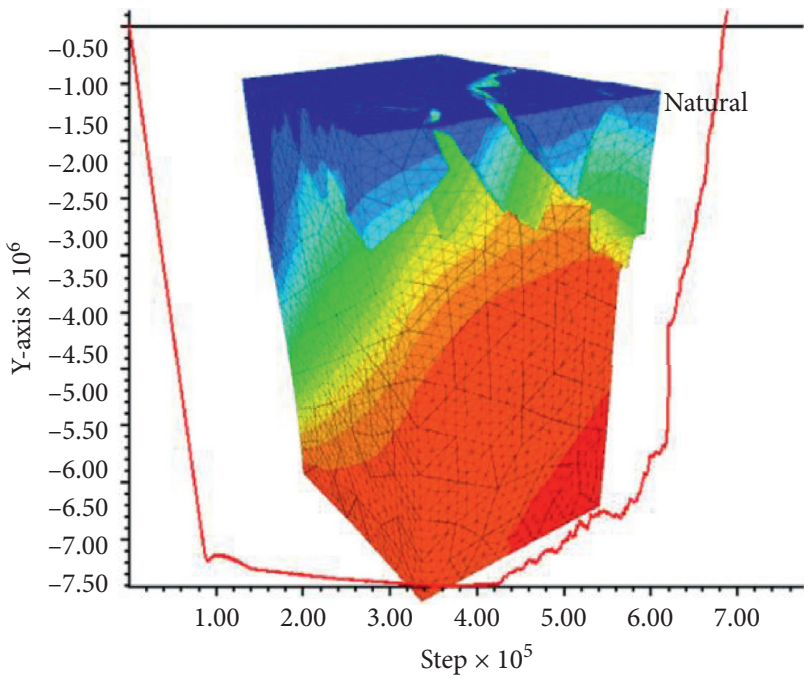

(a)

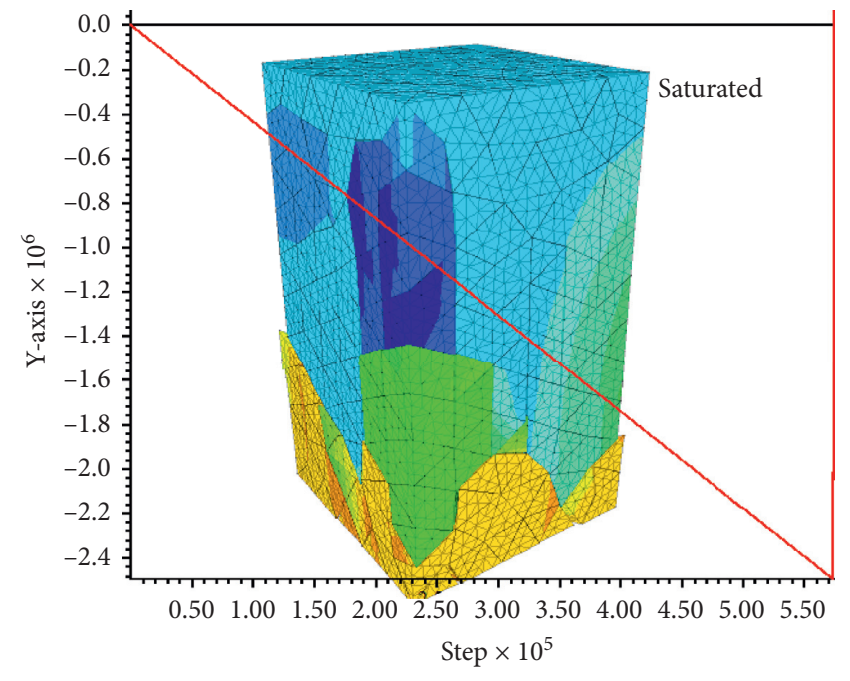

(b)

FIgURE 7: Numerical test on the uniaxial compressive strength of the rock mass.

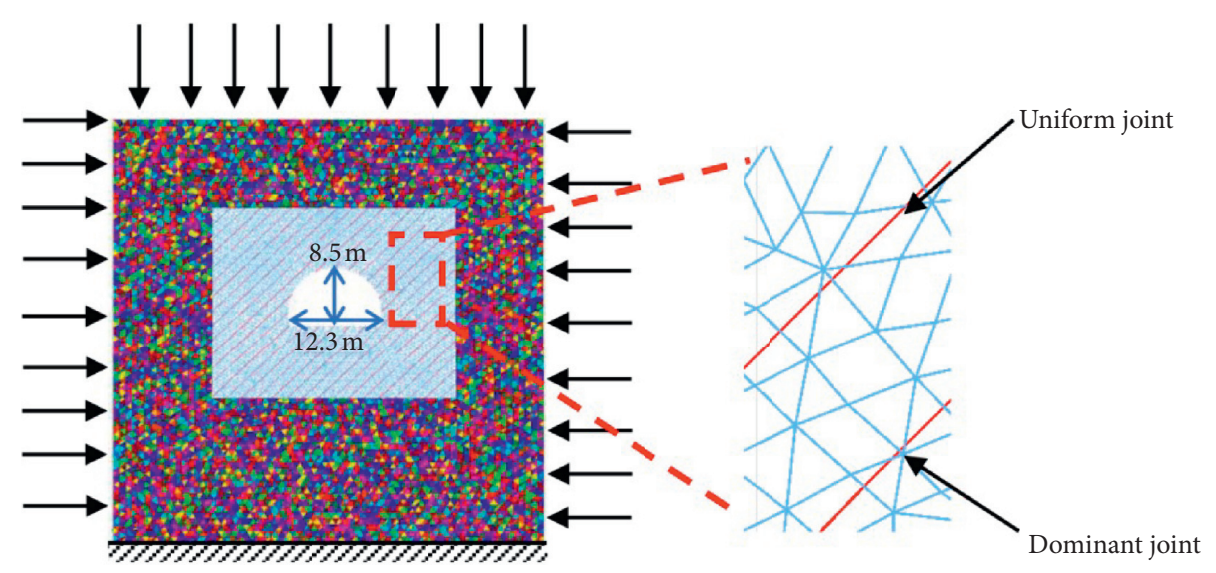

FIgURE 8: Numerical computation model. 

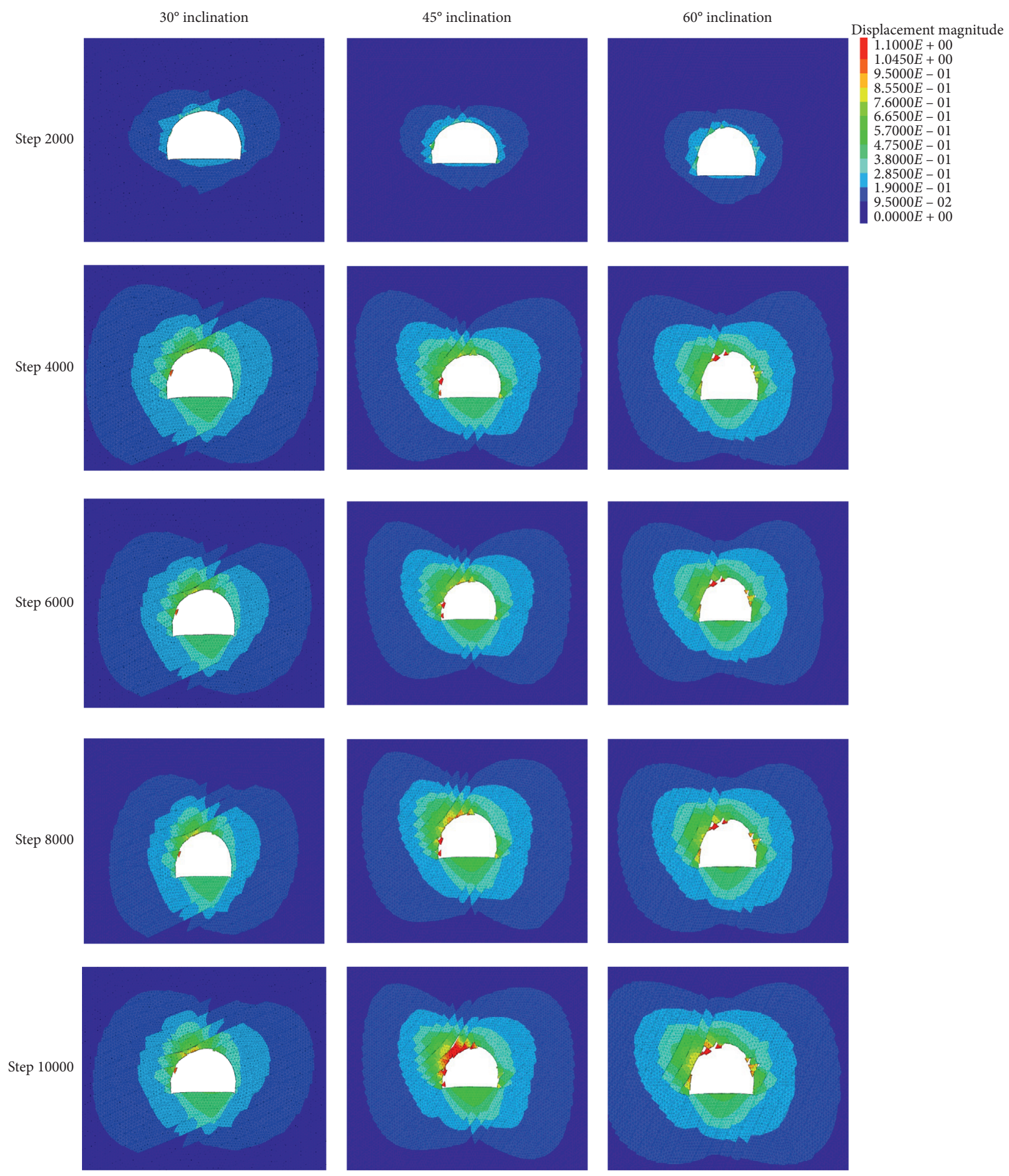

Figure 9: Distribution of surrounding rock displacement under different joint inclinations.

asymmetry. The maximum bending deformation corresponding to the $60^{\circ}$ joint inclination was $0.8 \mathrm{~m}$, and the displacement deformation essentially stopped when the calculation reached 9000 steps. A separation layer developed at a depth of approximately $4 \mathrm{~m}$ in the surrounding rock.

4.4.2. Trend in the Maximum Principal Stress Expansion. The original stress field is rearranged after the excavation of a tunnel. The distribution of the maximum principal stress is an important basis for judging the stability of the geotechnical engineering, and it is an important index for understanding the range of influence of the excavation. As shown in Figure 10, the maximum principal stress transferred to a greater depth into the surrounding rock with the deformation of the surrounding rock, and the range of influence increased. After the tunnel deformation became stable, the maximum principal stress was concentrated in the vault and the bottom plate of the tunnel, and the maximum principal stress of the vault reached $32 \mathrm{MPa}$ (showing a stress 
concentration coefficient of 1.8). The maximum major principal stress of the vault occurred at $11 \mathrm{~m}$ from the tunnel wall. At increasing depth of the surrounding rock, the major principal stress decreased. At a distance of $16 \mathrm{~m}$ from the tunnel wall, the major principal stress transitioned to the original rock stress state, indicating that the range of influence of tunnel excavation was up to $16 \mathrm{~m}$.

4.5. Impact of Different Buried Depth Conditions on the Surrounding Rock of the Tunnel. The above analysis shows that the deformation of the surrounding rock is most evident when the joint inclination angle is $45^{\circ}$ under the same buried depth. Therefore, this section considers the dominant joint with a $45^{\circ}$ inclination angle as the structural condition to study the variation in the stress, strain, and plastic zone of the surrounding rock caused by tunnel excavation under different buried depths.

Combined with the site-tunnel buried depth conditions, three tunnel excavation depths $H$ were selected: 250, 330, and $500 \mathrm{~m}$. The displacement distribution of the surrounding rock after tunnel excavation under the three buried depth conditions is shown in Figure 11. The simulation results show that (1) the deformation of the surrounding rock of the tunnel under the influence of the dominant joint is asymmetric under different buried depth conditions, showing that the left side deformation is larger than the right side, the maximum deformation position is located at the left shoulder socket of the tunnel, and the maximum deformation amount and deformation range of the tunnel gradually expand with an increase in buried depth and (2) for $H=250 \mathrm{~m}$, the tunnel does not have obvious damage, the tunnel section shape is essentially good, and the maximum displacement is $350 \mathrm{~mm}$. When $H=330 \mathrm{~m}$, the left shoulder socket of the tunnel appears to have a detached layer, the surrounding rock of the tunnel has bending damage, and the maximum displacement is $520 \mathrm{~mm}$. When $H=500 \mathrm{~m}$, thin-plate bending and damage occurred at the left side and the left shoulder fossa of the tunnel, and the maximum deformation is $1100 \mathrm{~mm}$.

The distribution characteristics of the plastic zone of the surrounding rock excavated by tunnels with different depths are shown in Figure 12. The simulation results show the following. (1) The distribution of the plastic zone is crossshaped, with vertical dominant joints and parallel dominant joints in the direction of the cross axis. As the burial depth increases, the plastic zone expands gradually and the plastic zone of the surrounding rock mass has shear failure. Primarily, the shear displacement direction is closely related to the direction of the joint surface. (2) When $H=250 \mathrm{~m}$, the tunnel roof and left shoulder form two shear failure zones and the vertical joints in these zones are in the form of a strip. The width of the shear band gradually decreases with increasing depth in the surrounding rock, and a "V" shear failure zone forms at the bottom of the tunnel, with the boundary of the " $\mathrm{V}$ " opening intersecting the bottom corner of the tunnel. (3) When $H=350 \mathrm{~m}$, the top of the tunnel and the left shoulder failure zone intersect, and the two shear zones gradually combine through the shear action, forming an "M" plastic zone. The bottom shear zone gradually transitions to the "W" shape under the action of in situ stress. Both ends of the "W" shape intersect the tunnel bottom angle and expand upward along the side, gradually closing up with the upper "M"-type plastic zone. (4) When $H=500 \mathrm{~m}$, the plastic zone inherits the trend when $H=350 \mathrm{~m}$, the two plastic zones at the top and the shoulder form a large-scale penetration, and the bottom "W" plastic zone completely closes with the upper "M" model. Eventually, a larger " $\mathrm{p}$ " plastic zone forms.

The maximum principal stress distribution of the surrounding rock under different buried depths is shown in Figure 13. The simulation results demonstrate the following. (1) The maximum principal stress increases with the increase in buried depth, and the distribution law changes with buried depth. (2) When $H=250 \mathrm{~m}$, a stress concentration is present at the bottom angle of both sides of the tunnel and the upper and lower parts of the tunnel, and the maximum principal stress is $16 \mathrm{MPa}$. When $H=350 \mathrm{~m}$, the maximum principal stress is $19 \mathrm{MPa}$. (3) When $H=500 \mathrm{~m}$, the stress of the surrounding rock is concentrated at 1 to 1.5 times the hole diameter from the top and bottom plate, the width of the stress-concentrated area is approximately the same as the hole diameter, and the maximum principal stress is $32 \mathrm{MPa}$.

4.6. Effect of Softening of the Surrounding Rock on the Deformation of the Tunnel. During the construction of the No. 2 inclined shaft of the Muzhailing Tunnel, water gushing from the fissure was often encountered, and the deformation of the tunnel was found to be more significant in areas where water gushing was large. According to Section 2.4.2, the uniaxial strength of carbonaceous slate after water absorption was 0.4 times the uniaxial strength in the natural state, and the rock strength significantly decreased. Therefore, it is necessary to analyze the influence of water absorption and softening on the deformation of the tunnel. Combined with the difficulty of on-site engineering operations, the influence of water absorption and softening of surrounding rock on the surrounding rock of the tunnel was analyzed under working conditions of a tunnel burial depth of $500 \mathrm{~m}$ and a dominant joint angle of $45^{\circ}$.

By reducing the strength of surrounding rock to $40 \%$ of the strength before water absorption, we compared the deformation field, plastic zone, and stress field distribution characteristics of the surrounding rock before and after water absorption (Figure 14). (1) The characteristics of the deformation distribution of the surrounding rock before and after water absorption change greatly. The deformation of the tunnel before water absorption is mainly distributed in the left shoulder socket with a maximum deformation of $1200 \mathrm{~mm}$. The left shoulder socket tends to be unstable, while the deformation of other parts is small and there is no instability. After water absorption and softening, the deformation of the surrounding rock at the left shoulder socket is the largest, with a maximum of $1900 \mathrm{~mm}$, while the tunnel floor and the right side also have large deformation, and the deformation range of the surrounding rock extends to a greater depth. The hole has a symmetrical "C" shape, which 


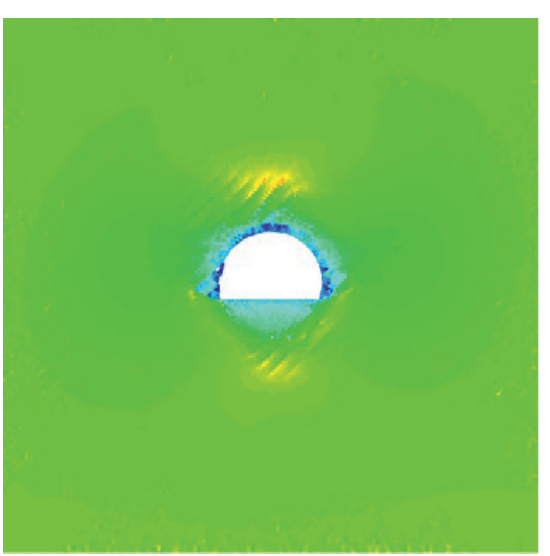

(a) stress

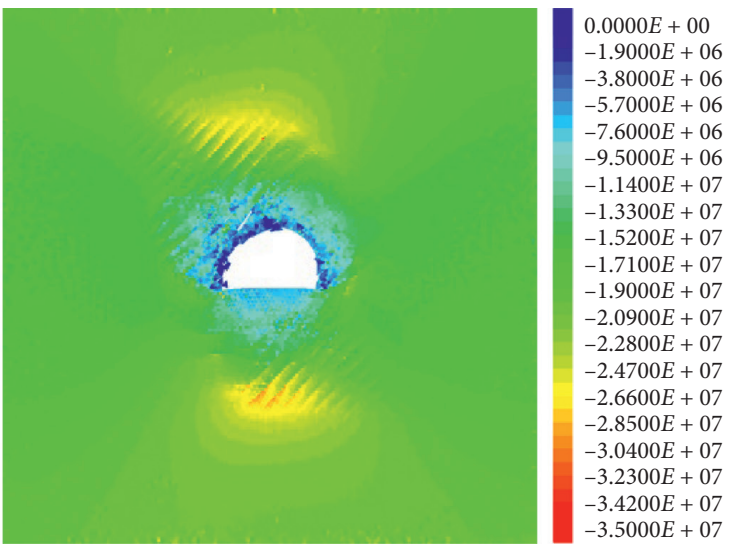

(b)

Figure 10: Distribution of maximum principal stress corresponding to a $45^{\circ}$ inclination of joints: (a) step 2000 and (b) step 6000.

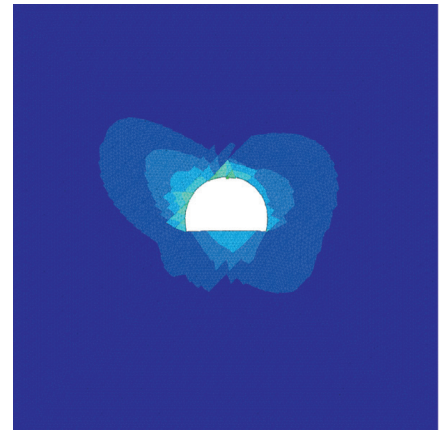

(a)

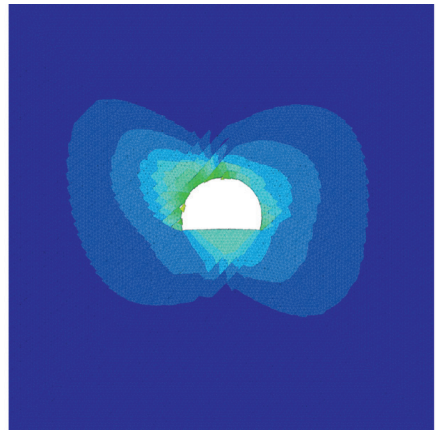

(b)

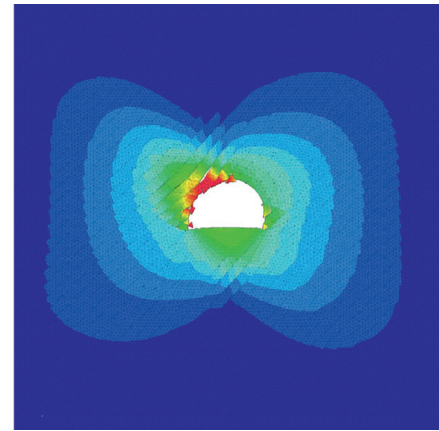

(C)

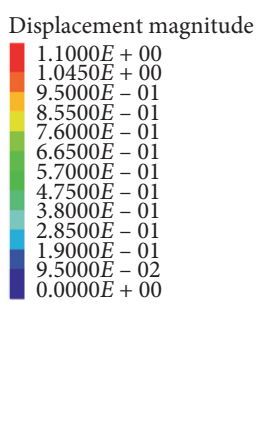

(b) $H=350 \mathrm{~m}$, and (c)

FigURE $11:$
$H=500 \mathrm{~m}$

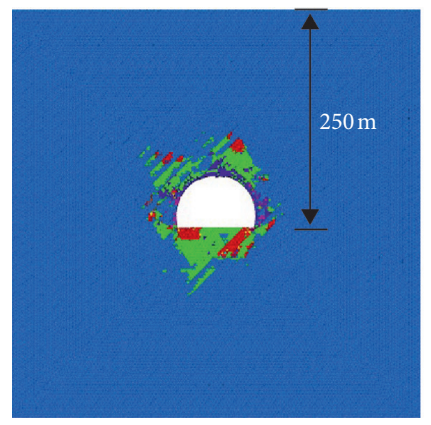

(a)

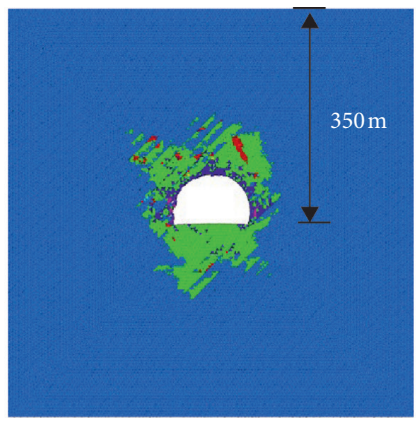

(b)

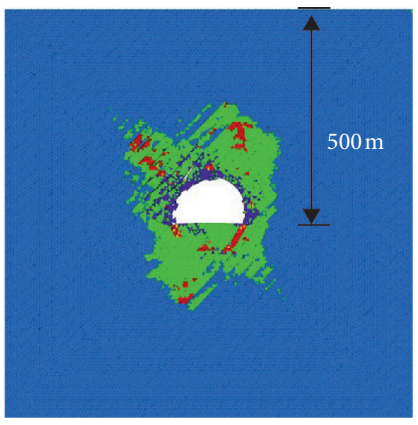

(c)

FIgURE 12: Distribution characteristics of the plastic zone at different depths: (a) $H=250 \mathrm{~m}$, (b) $H=350 \mathrm{~m}$, and (c) $H=500 \mathrm{~m}$.

indicates that the decrease of the surrounding rock strength after the water absorption softening helps control the deformation of the tunnel, while the dominant joints have an effect on the deformation direction. (2) The plastic zone of the surrounding rock is also evidently expanded after water absorption softening, which is affected by the decrease in the strength of the surrounding rock. Furthermore, the upper plastic zone completely joins and the dominant joints still affect the distribution characteristics of the plastic zone. The radius of the plastic zone after water absorption softening can reach $14.5 \mathrm{~m}$, which is approximately $4.2 \mathrm{~m}$ more than before water absorption, indicating that the distribution range is mainly controlled by the strength of the surrounding rock. (3) The stress distribution of the surrounding rock also changes greatly before and after water absorption softening. The maximum principal stresses before and after water absorption are concentrated in the deep surrounding rock at the top and bottom of the tunnel, the maximum 


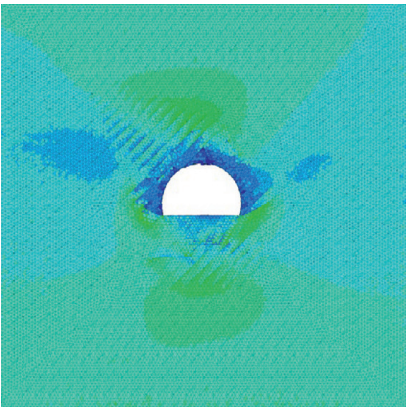

(a)

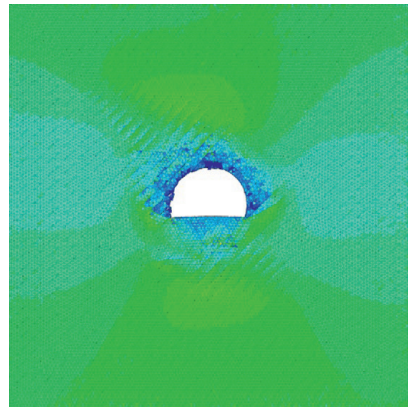

(b)

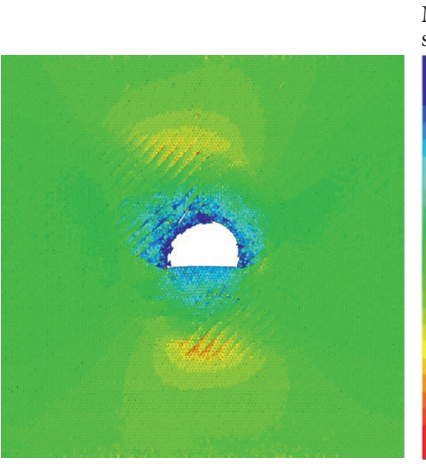

(c)

Min. prin. (max. compression) stress

$0.0000 E+00$

$-3.2000 E+06$

$-6.4000 E+06$

$-9.6000 E+06$

$-1.2800 E+07$

$-1.6000 E+07$

$-1.9200 E+07$

$-2.2400 E+07$

$-2.5600 E+07$

$-2.8800 E+07$

$-3.2000 E+07$

$-3.5000 E+07$

Figure 13: Distribution of maximum principal stress under different burial depths: (a) $H=250 \mathrm{~m}$, (b) $H=350 \mathrm{~m}$, and (c) $H=500 \mathrm{~m}$.
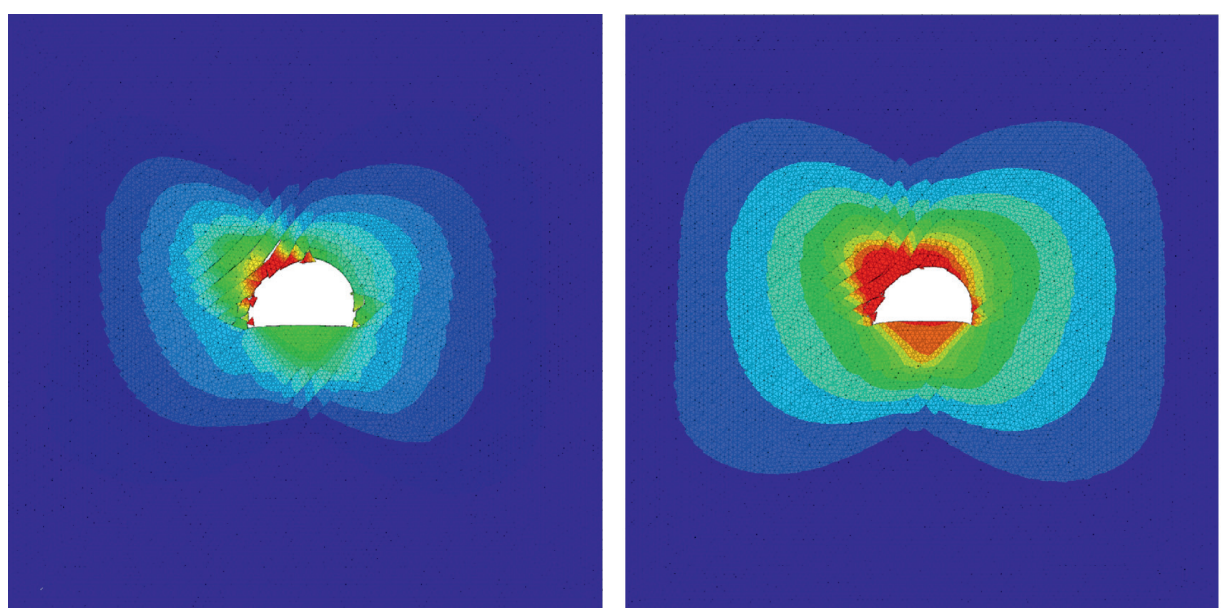

Displacement magnitude

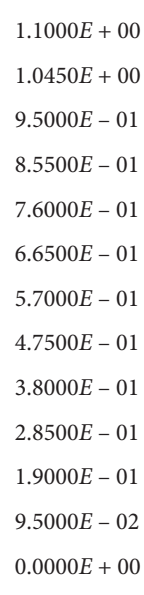

(a)
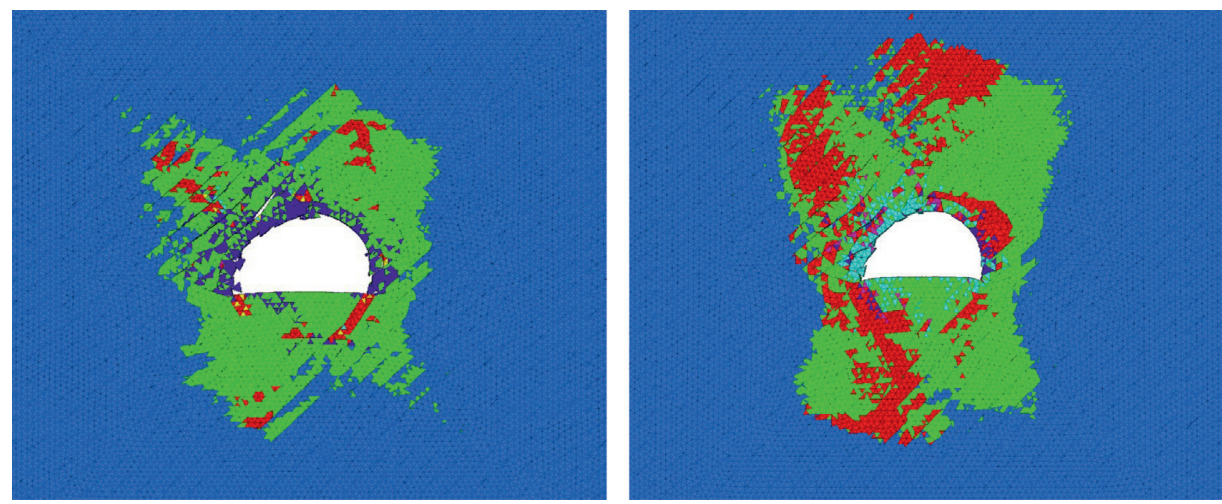

Block

Color: State

Shear-n shear-p

Shear-n shear-p tension- $p$

Shear-p

Shear- $p$ tension- $p$

Tension-n shear-p tension-p

Tension-n tension- $\mathrm{p}$

Tension-p

(b)

Figure 14: Continued. 

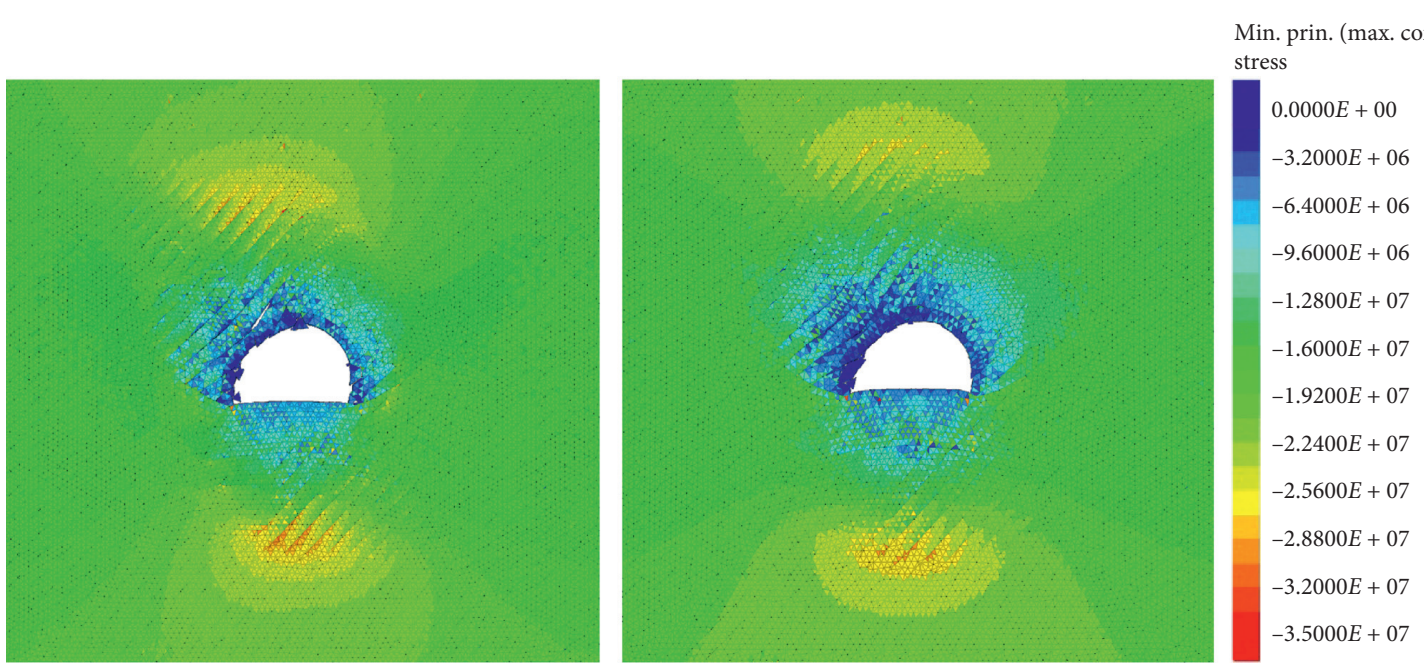

(c)

Figure 14: Deformation characteristics of the surrounding rock of the tunnel under water absorption and softening: (a) change in the surrounding rock displacement before and after water absorption, (b) changes in the plastic zone of the tunnel before and after water absorption, and (c) changes in the maximum principal stress field of the tunnel before and after water absorption.

principal stress concentration area after water absorption moves to 0.5 times the diameter of the hole to a greater depth, and the maximum principal stress value decreases by approximately $4 \mathrm{MPa}$ after water absorption softening.

\section{Conclusions}

In view of the large deformation of the surrounding rock during the construction of the No. 2 inclined shaft of the Muzhailing Tunnel, the deformation characteristics and influence of the surrounding rock of the tunnel under the original supporting form were analyzed. The following conclusions are drawn:

(1) The initial support of the No. 2 inclined shaft of the Muzhailing Tunnel was seriously damaged, and the deformation of the surrounding rock of the tunnel was asymmetric. The deformation on the left side was significantly larger than that on the right side, and the area with a deformation greater than $0.25 \mathrm{~m}$ accounted for $41 \%$ of the total length of the tunnel. In addition, when the buried depth was more than $500 \mathrm{~m}$, serious deformation of the surrounding rock exceeding $1 \mathrm{~m}$ was observed.

(2) According to the field investigation, the laboratory experiment, and the field-monitoring data analysis, the surrounding rock of the No. 2 inclined shaft of the Muzhailing Tunnel was relatively broken, the lithology was mainly carbonaceous slate, the joints and fractures were well developed, and the area was subjected to extremely high stress. The uniaxial compressive strength after 24 hours of water absorption was markedly lower than that of carbonaceous slate in the natural condition. The uniaxial compressive strength and elastic modulus of the rock with a $45^{\circ}$ joint inclination were relatively low when compared with inclinations of $30^{\circ}$ and $60^{\circ}$. Therefore, the main factors affecting the deformation of the thin-layer rock of the Muzhailing Tunnel included the joint inclination angle, buried depth of the tunnel, and softening of the surrounding rock due to water absorption.

(3) Through the numerical simulation results, it can be concluded that under the same buried depth, the deformation of surrounding rock was maximum for a $45^{\circ}$ joint inclination. At the $45^{\circ}$ joint inclination, the deformation and failure of the tunnel was intensified with an increase in burial depth. When the burial depth was $500 \mathrm{~m}$, thin-plate bending and damage occurred at the left side and the left shoulder fossa of the tunnel; after the surrounding rock was softened by water absorption, the floor of the tunnel, the left shoulder socket, and the right side of the tunnel deformed greatly and the deformation range of the surrounding rocks extended to a greater depth.

\section{Data Availability}

All the data included in this study are available upon request by contact with the corresponding author.

\section{Conflicts of Interest}

The authors declare that there are no conflicts of interest regarding the publication of this article.

\section{Acknowledgments}

Thanks to the academician He Manchao of the State Key Laboratory for GeoMechanics and Deep Underground Engineering for his valuable comments on the writing and revision of this manuscript. The authors would like to thank 
Uni-edit (http://www.uni-edit.net) for editing and proofreading this manuscript. This work was supported by the National Key Research and Development Plan (grant no. 2016YFC0600901) and the Special Fund for Basic Scientific Research Business Expenses of Central Universities (grant no. 2015QB02).

\section{References}

[1] S. Chen, D. Yin, N. Jiang, F. Wang, and Z. Zhao, "Mechanical properties of oil shale-coal composite samples," International Journal of Rock Mechanics and Mining Sciences, vol. 123, Article ID 104120, 2019.

[2] N. Zhang, W. Liu, Y. Zhang, P. F. Shan, and X. L. Shi, "Microscopic pore structure of surrounding rock for underground strategic petroleum reserve (SPR) caverns in bedded rock salt," Energies, vol. 13, no. 7, p. 1565, 2020.

[3] Y. Zhang, S. G. Cao, N. Zhang, and C. Z. Zhao, "The application of short-wall block backfill mining to preserve surface water resources in northwest China," Journal of Cleaner Production, vol. 261, Article ID 121232, 2020.

[4] P. Shan and X. Lai, "An associated evaluation methodology of initial stress level of coal-rock masses in steeply inclined coal seams, Urumchi coal field, China," Engineering Computations, vol. 37, no. 6, pp. 2177-2192, 2020.

[5] C. X. Wang, B. T. Shen, J. T. Chen et al., "Compression characteristics of filling gangue and simulation of mining with gangue backfilling: an experimental investigation," Geomechanics and Engineering, vol. 20, no. 6, pp. 485-495, 2020.

[6] D. Ren, D. Zhou, D. Liu, F. Dong, S. Ma, and H. Huang, "Formation mechanism of the upper Triassic Yanchang Formation tight sandstone reservoir in Ordos Basin-Take Chang 6 reservoir in Jiyuan oil field as an example," Journal of Petroleum Science and Engineering, vol. 178, pp. 497-505, 2019.

[7] N. Jiang, C. Wang, H. Pan, D. Yin, and J. Ma, "Modeling study on the influence of the strip filling mining sequence on mining-induced failure," Energy Science \& Engineering, vol. 8, no. 6, pp. 2239-2255, 2020.

[8] H. Huang, T. Babadagli, X. Chen, H. Z. Li, and Y. M. Zhang, "Performance comparison of novel chemical agents for mitigating water-blocking problem in tight gas sandstones," SPE Reservoir Evaluation \& Engineering, vol. 2020, pp. 1-9, 2020.

[9] D. Brox and H. Hagedorn, "Extreme deformation and damage during the construction of large tunnels," Tunnelling and Underground Space Technology, vol. 14, no. 1, pp. 23-28, 1999.

[10] E. Hoek and P. Marinos, "Predicting tunnel squeezing problems in weak heterogeneous rock masses"” Tunnels \& Tunnelling International, vol. 32, no. 11, pp. 45-51, 2000.

[11] G. Liu, F. Y. Zhang, X. Z. Li, and Z.-C. Yang, "Research on large deformation and its mechanism of Muzhailing Tunnel," Chinese Journal of Rock Mechanics and Engineering, vol. 24, no. s2, pp. 5521-5526, 2005.

[12] M. A. Meguid and R. K. Rowe, "Stability of D-shaped tunnels in a Mohr Coulomb material under anisotropic stress conditions," Canadian Geotechnical Journal, vol. 43, no. 43, pp. 273-281, 2006.

[13] X. Guo, Z. Tan, L. Li, and N. Luo, "Deformation and failure mechanism of layered soft rock tunnel under high stress," China Civil Engineering Journal, vol. 50, pp. 38-44, 2017.

[14] T. C. Yu, "Study on large deformation control technology of tunnel in soft rock," China Civil Engineering Journal, vol. 50, pp. 112-117, 2017.
[15] C. Cao, C. Shi, M. Lei, W. Yang, and J. Liu, "Squeezing failure of tunnels: a case study," Tunnelling and Underground Space Technology, vol. 77, no. 7, pp. 188-203, 2018.

[16] X. Sun, B. Zhang, L. Gan, Z. Tao, and C. Zhao, "Application of constant resistance and large deformation anchor cable in soft rock Highway tunnel," Advances in Civil Engineering, vol. 2019, Article ID 4347302, 19 pages, 2019.

[17] Chinese Academy of Geological Sciences, Test Report on Hydraulic Fracturing Ground Stress of Muzhailing Tunnel on the Highway from Weiyuan (Luyuan) to Wudu (Liangshui) of Gansu Province, Chinese Academy of Geological Sciences, Beijing, China, 2013.

[18] G. Feng, Y. Kang, X. Wang, Y. Hu, and X. Li, "Investigation on the failure characteristics and fracture classification of shale under Brazilian test conditions," Rock Mechanics and Rock Engineering, vol. 53, no. 7, pp. 3325-3340, 2020.

[19] G. Feng, X. Wang, M. Wang, and Y. Kang, "Experimental investigation of thermal cycling effect on fracture characteristics of granite in a geothermal-energy reservoir," Engineering Fracture Mechanics, vol. 235, Article ID 107180, 2020.

[20] Z.-D. Cui, D.-A. Liu, and F.-Q. Wu, "Influence of dip directions on the main deformation region of layered rock around tunnels," Bulletin of Engineering Geology and the Environment, vol. 73, no. 2, pp. 441-450, 2014.

[21] N. Bahrani and J. Hadjigeorgiou, "Influence of stope excavation on drift convergence and support behavior: insights from 3D continuum and discontinuum models," Rock Mechanics and Rock Engineering, vol. 51, no. 8, pp. 2395-2413, 2018.

[22] X. B. Hou, "U-shape steel frame and bolt-mesh-anchor coupling support technology in deep soft rock coal roadway by 3DEC," Safety in Coal Mines, vol. 49, no. 7, pp. 134-137, 2018.

[23] X. Sun, G. Li, C. Zhao, Y. Liu, and C. Miao, "Investigation of deep mine shaft stability in alternating hard and soft rock strata using three-dimensional numerical modeling," Processes, vol. 7, no. 1, p. 2, 2018.

[24] W. H. Tan, Z. H. Sun, N. Li, and X. H. Jiang, "Stochastic threedimensional joint geometry model and the properties of REV for a jointed rock mass," Advanced Materials Research, vol. 1079-1080, pp. 266-271, 2014.

[25] Itasca Consulting Group, Inc. 3DEC User Manual, Itasca Consulting Group, Inc., Minneapolis, MN, USA, 2016.

[26] S.-Q. Yang, M. Chen, H.-W. Jing, K.-F. Chen, and B. Meng, “A case study on large deformation failure mechanism of deep soft rock roadway in Xin'an coal mine, China," Engineering Geology, vol. 217, pp. 89-101, 2017.

[27] D. Liu, Z. Gu, R. Liang et al., "Impacts of pore-throat system on fractal characterization of tight sandstones," Geofluids, vol. 2020, no. 9, Article ID 4941501, 17 pages, 2020.

[28] S. Hu, Y. Tan, H. Zhou et al., "Anisotropic modeling of layered rocks incorporating planes of weakness and volumetric stress," Energy Science \& Engineering, vol. 8, no. 3, pp. 789-803, 2020.

[29] X. Wang, W. Yuan, Y. T. Yan, and X. Zhang, "Scale effect of mechanical properties of jointed rock mass: a numerical study based on particle flow code," Geomechanics and Engineering, vol. 21, no. 3, pp. 259-268, 2020.

[30] E. Hoek, C. Carranza-Torres, and B. Curkum, "Hoek-Brown failure criterion-2002 edition," in Proceedings of the Fifth North American Rock Mechanics Symposium, pp. 267-273, Toronto, Canada, July 2002. 